\title{
Gleichbehandlung und Transparenz als gemeinschaftsrechtliche Prinzipien der staatlichen Auftragsvergabe
}

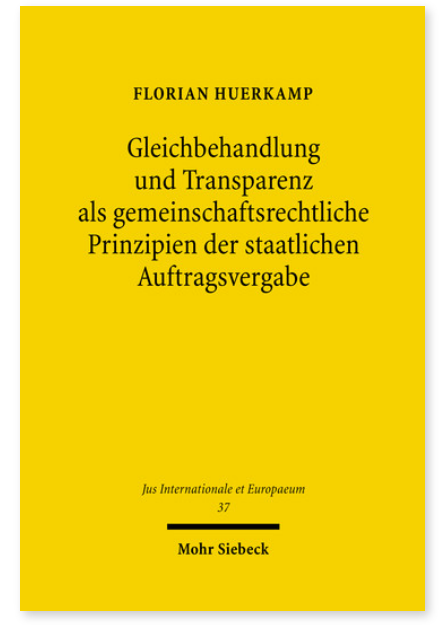

2010. XXIV, 361 Seiten. JusIntEu 37

ISBN 978-3-16-151176-9

DOI 10.1628/978-3-16-151176-9

eBook PDF 79,00€

ISBN 978-3-16-150231-6

fadengeheftete Broschur 79,00€
Das Vergaberecht wird mehr und mehr von einem »matter of policy » zu einem »matter of principle ». Verantwortlich hierfür ist der gemeinschaftsrechtliche Grundsatz der Gleichbehandlung, dem der EuGH auch eine Verpflichtung zur transparenten Auftragsvergabe entnimmt. Die Ausweitung des Anwendungsbereichs des Gleichbehandlungsgrundsatzes sowohl inhaltlicher Art - er wird zum umfassenden Maßstab staatlicher Beschaffung, der mehr verlangt als lediglich die gleiche Anwendung der Ausschreibungsbedingungen auf alle Bewerber - als auch seiner Reichweite nach birgt theoretische und praktische Probleme. Florian Huerkamp entwirft eine Dogmatik der grundlegenden gemeinschaftsrechtlichen Vergabeprinzipien, in der die aus dem Gleichbehandlungsprinzip folgenden Pflichten für die nationalen Vergabestellen so strukturiert werden, dass sie eine möglichst rechtssicherere Anwendung durch die Beschaffungsstellen zulassen.

Florian Huerkamp Geboren 1980; Studium der Rechtswissenschaft in Regensburg, Sussex und Oxford; 2009 Promotion; Wissenschaftlicher Mitarbeiter an der Universität Bonn und Rechtsreferendar am Landgericht Köln.

Jetzt bestellen:

https://mohrsiebeck.com/buch/gleichbehandlung-und-transparenz-als-gemeinschaftsrechtliche-prinzipien-der-staatlichenauftragsvergabe-9783161511769?no_cache=1

order@mohrsiebeck.com

Telefon: +49 (0)7071-923-17

Telefax: +49 (0)7071-51104 